\title{
Media analysis of the representations of fusion and other future energy technologies
}

\author{
Ana Delicado, Luísa Schmidt, Sérgio Pereira, Christian Oltra, Ana Prades
}

\begin{abstract}
Media representations of energy have a relevant impact on public opinion and public support for investment in new energy sources. Fusion energy is one among several emerging energy technologies that requires a strong public investment on its research and development. This paper aims to characterise and compare the media representations of fusion and other emerging energy technologies in Portugal and in Spain. The emerging energy technologies selected for analysis are wave and tidal power, hydrogen, deep sea offshore wind power, energy applications of nanotechnology, biofuels from microalgae and IV generation nuclear fission. This work covered the news published in a selection of newspapers in Portugal and Spain between January 2007 and June 2013.
\end{abstract}

\section{INTRODUCTION}

NuClear fusion is considered by some as the most promising energy technology of the future, raising the hope for a fully accomplishment of our societies' growing demand for energy and concurrently for more sustainable and less costly energy supply systems. To some extent, nuclear fusion is conceived as a unique form of energy that is unrivalled in terms of power, efficiency, cleanliness and safety. However, for its critics, it is very unlikely that nuclear fusion could deliver all that it promises in the forthcoming decades, moreover at this stage of development where it has yet to prove its commercial viability. Withal there are other emergent energy technologies that can be regarded as virtual solutions to the energy problem which may compete with nuclear fusion not only for political and economic support but also for broad public acceptance.

Social representations are key elements to assess the degree of public acceptance of these other emergent technologies, namely when compared with nuclear fusion with regard to the challenging possibilities of future energy scenarios. The analysis of news content can be a powerful method to achieve such an understanding, namely by identifying which topics,

Manuscript received April 6, 2015. The research was supported by EFDA European Fusion Development Agreement through its SERF Socio-Economic Research on Fusion Programme (Task Agreement WP13-SERF-ACIF).IPFNIST is the Portuguese partner in Eurofusion.

Ana Delicado is with the Institute of Social Sciences of the University of Lisbon, Av. Prof. Aníbal de Bettencourt, 9 1600-189 Lisbon, Portugal (ana.delicado@ics.ulisboa.pt).

Luísa Schmidt is with the Institute of Social Sciences of the University of Lisbon, Av. Prof. Aníbal de Bettencourt, 9 1600-189 Lisbon, Portugal (mlschmidt@ics.ulisboa.pt).

Sergio Pereira is with the Institute of Social Sciences of the University of Lisbon, Av. Prof. Aníbal de Bettencourt, 9 1600-189 Lisbon, Portugal.

Christian Oltra is with CISOT-CIEMAT. Gran Via de les Corts Catalanes 604, 4, 2, 08007 Barcelona, Spain (christian.oltra@ciemat.es).

Ana Prades is with CISOT-CIEMAT. Gran Via de les Corts Catalanes 604, 4, 2, 08007 Barcelona, Spain (ana.prades@ ciemat.es). valuations and constructed views of energy related subjects are presented in the media and to what extent are they important in drawing comparisons between nuclear fusion and other emergent energy technologies.

The work described in this paper is a follow-up of a previous analysis, which conducted an analysis of news from German, Spanish and Portuguese journals, as well as of international press, regarding fusion, focusing in particular in the representation of fusion and fission before and after the Fukushima accident [1]. Taking advantage of the database of news already collected, we complement it with the collection of news regarding other emerging energy generating technologies, in order to compare media representations.

The emerging energy technologies selected for analysis are wave and tidal power, hydrogen, deep sea offshore wind power, energy applications of nanotechnology, biofuels from microalgae and IV generation nuclear fission. This work covered the news published in a selection of newspapers in Portugal and Spain between January 2007 and June 2013.

\section{Methodology}

Our study draws on a comparative analysis of media discourse about fusion and other emerging energy technologies in Portuguese and Spanish newspapers and encompasses coverage, thematic frames, valuations, risks or benefits associated with the various energy technologies. To begin with it was crucial to select a group of technologies that are currently at a similar stage of development and simultaneously have some relevance to each country's socioeconomic and political contexts. Our main list included: off-shore wind power, energy-related applications of nanotechnology, hydrogen, wave power, tidal power and biofuels from microalgae. Additionally and regarding the fact that Spain has nuclear energy and Portugal does not, we decided to include IV nuclear generation (IV Gen Reactors) as an extra subject only for the Spanish case analysis.

The study followed a quantitative content analysis of news with the aim of identifying the most frequent themes, valuations and propositions that ultimately shape media discourse about the selected energy technologies. Content analysis also enabled us to observe some connections between different features and topics of written news which added meaningful insights to our analysis.

The sample was extracted from a collection of written news published on online editions of national mainstream and business newspapers between January 2007 and June 2013. We choose 2007 as starting date since it was the year of the beginning of the construction of the ITER research device (a 
milestone in nuclear fusion development) and June 2013 as a concluding date, thus completing a six and a half year period which seemed wide enough to gather a reasonable amount of articles. All section of newspapers (editorials, economic, political, scientific sections, etc.) and all forms of presentation (news in brief, opinion columns, interviews, reportage, etc.) were considered for the articles search and sampling.

After the collection of all articles we found that some energy technologies such as off-shore wind power or wave power account for one hundred or more articles each, while biofuels from microalgae or energy-related applications of nanotechnology account for less than thirty articles each. In order to produce a more balanced sample we decided to extract a subsample of the technologies more abundantly covered by selecting only the articles published in the first two weeks of each month.

The subsample for Portugal comprised 311 articles, 44\% of which were published by Público, considered the standard of quality for Portuguese daily newspapers, followed by Diário de Notícias, with $30 \%$ and Jornal de Negócios, with only $25 \%$ of the total records.

Of the 404 articles that comprise the Spanish subsample, the top three highest values correspond to the articles published by three of the major general-interest daily newspapers in Spain: ABC, with 33\%, El Mundo, with 21.5\% and El País, with 18\% of all records. These are far ahead from all the other newspapers especially from Público.es (a daily national) and La Vanguardia (a nationwide daily written in Catalan).

The data corpus was subjected to statistical analysis in SPSS (Statistical Package for the Social Sciences) which encompassed univariate analysis with frequency distribution of single variables and bivariate analysis with crosstabulations and contingency tables. Bivariate analysis was aimed at identifying the relationship between independent and dependent variables such as the "technology mainly focused in the article" and "thematic frames". The data outputs were finally analyzed according to our main objectives: i) comparisons between the various emergent energy technologies with regard to the amount of articles published, degree of information, themes, valuations and statements or arguments presented towards each technology; b) comparisons between Portuguese and Spanish most significant results

Social representations about the different energy technologies could also be grasped by following a more indepth analysis. With this objective in mind we employed a qualitative method based on a template with predefined codes. The data corpora was based on a purposive sample. We selected one article about each technology within each country' sub-samples, thus analysing 15 articles in total. The guiding criteria for this selection were the length and depth of information (found mostly in as reportages and interviews). News in brief were therefore excluded. The number of articles selected corresponded to the number of technologies covered in each country. Thus, for the Portuguese analysis we collected seven articles while for the Spanish analysis we selected eight.

\section{RESULTS OF THE QUANTITATIVE ANALYSIS}

Regarding the main technology focused in news articles, an overwhelming proportion of articles in Spanish newspapers between 2007 and 2012 (52\%) focus on multiple technologies (Figure 1). The second technology mainly focused is off-shore wind power but with a proportion significantly lower than the former. Biofuels from microalgae (3\%) and tidal power (1\%) are the least focused technologies. Nuclear fusion and Hydrogen show equal results (very close to those of wave power, nanotechnology and IV nuclear generation).

Off-shore wind power is the technology mainly focused in Portuguese newspapers (in 23\% of the articles) followed by hydrogen and wave power (both in 16\%) and nuclear fusion (in 12\%). Only $12 \%$ of Portuguese articles highlight multiple technologies, which contrasts significantly with the results from Spain.

The exception is tidal power. In fact, tidal power is more widely covered than nanotechnology and biofuels from microalgae both in Spain and Portugal (and IV nuclear generation in Spain), yet it is mainly focused in less articles than these other technologies. This is probably because the majority of articles written about tidal power also mention other sea energy related technologies such as offshore wind and wave power, to which it might be assigned a greater importance.

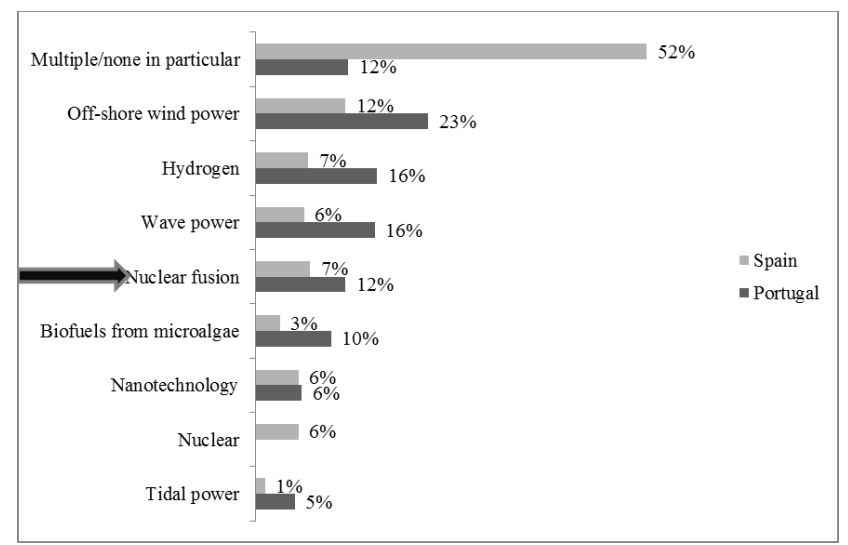

Fig. 1. Articles by main technology focused.

Regarding the distribution of articles per year and keyword in Portugal, some trends can be detected (Figure 2). Offshore wind power peaked in the news in 2010, when the main Portuguese electric company announced a project in the Portuguese coast, as well as investments in other countries in this form of energy. Wave power received more media coverage in 2009, mostly due to the beginning of an experimental project in Peniche [2]. Hydrogen merited a greater number of articles in 2007 and 2008, in view of technological innovations announced by international car manufacturers, but almost disappeared in 2012. As for Nuclear fusion there was a peak in the number of articles in 2009 followed by a downward trend henceforth. 


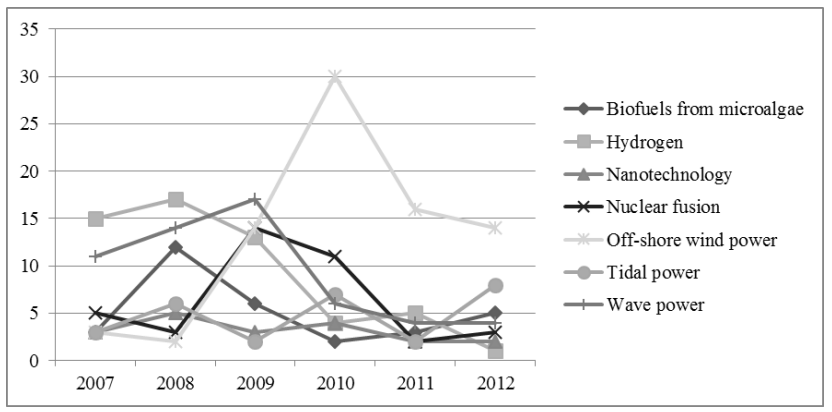

Fig. 2. Articles by keyword and year of publication in Portugal.

In Spain (Figure 3), hydrogen also peaked in 2008 and later in 2012 also as a result of international car manufactures innovations, but it was offshore wind power that received more media coverage in a later period, namely in 2011. The frequency of news on nuclear fusion was higher in 2010, the year of an important meeting of the board of directors of ITER, evolving with a relative visibility henceforth. Wave and tidal power have experienced a steady growth in media interest.

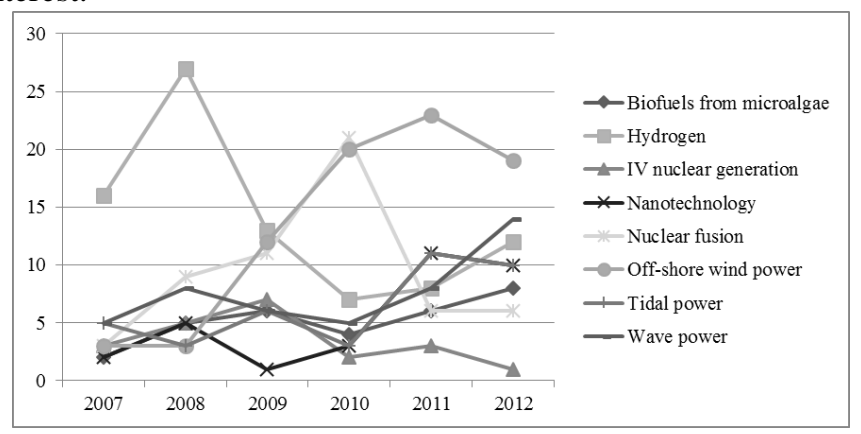

Fig 3. Articles by keyword and year of publication in Spain

\section{A. Themes of the articles}

Regarding the themes addressed in the news articles, the larger proportion of articles from Spanish newspapers focus primarily on "research projects and results" (36\%). "Shared investments and business cooperation", which is linked to the economic dimension, is the second most frequent theme (16\%) but with a difference of $20 \%$ in comparison to the aforementioned. There is also a fairly number of articles focusing on the state of the art of emerging energy technologies as it is seen by the proportion of articles associated with "progress and stage of development" (11\%). Policy related themes are mostly linked to "energy policy" (7\%) and much less to "regional or national development" (3\%). Only a few percentage of articles address environmental or safety related themes (the most frequently covered is "pollution or contamination" with only $4 \%$ of the total news) as well as "climate protection" (2\%). Culture related issues (such as consumption patterns, lifestyles and attitudes) are discarded in the primary thematic frame.

Portuguese newspapers address predominantly energy policy related content with $25 \%$ of the total news. This is quite similar to news coverage of renewable energy in Portugal [3]. "Investment costs on energy" is the second most focused theme with $22 \%$ of the total news, whereas "research projects and results" is the third with $22 \%$. Contrary to their Spanish counterparts, Portuguese newspapers tend to focus on a wider range of thematic dimensions such as policy, energy economy, and science, but here again environment and safety as well as culture or climate protection related subjects are underrepresented.

Regarding the primary theme by type of energy focused on the news articles in Portugal, a few aspects can be highlighted. Articles focused on off-shore wind power tend to give more relevance to economic (investment costs, shared investments) and policy issues. Hydrogen is mainly associated with research projects and with investment costs. Almost half the articles on wave power focus on energy policy. Articles on biofuels from microalgae also have mainly a scientific nature, though investment costs represent a third of primary themes. Nanotechnology articles also are focused on science. Articles on tidal power are characterized by a wide diversity of themes: energy policy, regional development, energy scenarios, and scientific events. Regarding nuclear fusion over a third of the articles concern research projects and results, followed by personnel matters and science policy. In comparison to other technologies, nuclear fusion is the one that more frequently raises the concept of future scenarios in news coverage, but it is also the one that is less often linked to investment costs, placing fusion in a realm still too far from the state of affairs in what concerns new solutions for energy production.

Spanish newspapers highlight different themes for each technology. Scientific aspects (research projects) are clearly dominant in articles on nuclear fusion and biofuels from microalgae, but also reach over half the sample on wave power and nanotechnology. Off-shore wind power is associated with shared investments and research projects. Half the articles on hydrogen concern research and a fourth of the articles mention pollution or contamination. Articles on nuclear energy underline the progress and stage of development. Articles on tidal power mention more frequently shared investments.

\section{B. Valuation of the articles}

Articles on emerging energy technologies in Portuguese newspapers are of a largely positive nature (Figure 4). Positive valuations are more frequent in the case of nanotechnology, biofuels from microalgae and off-shore wind power. The proportion of articles with a negative stance is slightly higher in what regards wave power, which is due to the controversies raised by some projects. A third of articles on nuclear fusion (which is the energy technology with a lower rate of positive articles) are neutral. This is in line with the generally positive coverage that is given to scientific issues in Portuguese newspapers [4] [5] [6].

By comparison, articles in Spanish newspapers tend to be more nuanced (Figure 5). The majority of technologies receive a neutral coverage, in particular fusion, biofuels from microalgae and off-shore wind power. Articles on nanotechnology and wave power are more frequently positive. Negative positions are a minority, but they can be found in 
articles concerning fusion, off-shore wind power and hydrogen.

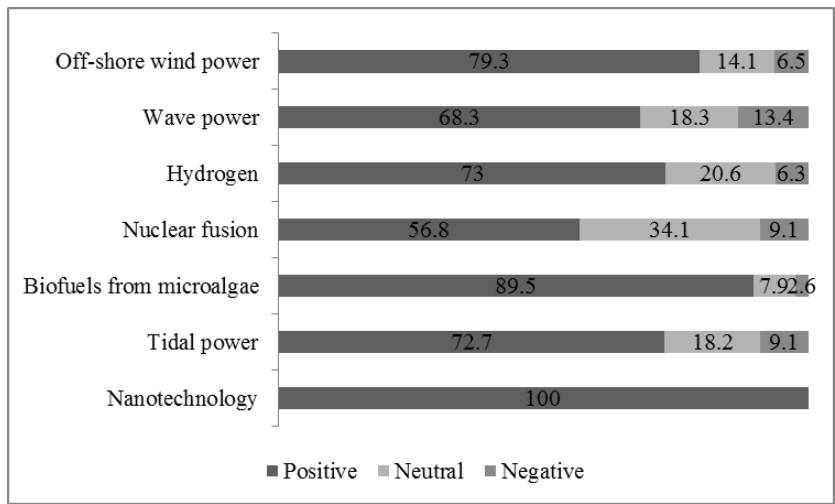

Fig.4 Valuation by type of technology in Portugal (\%)

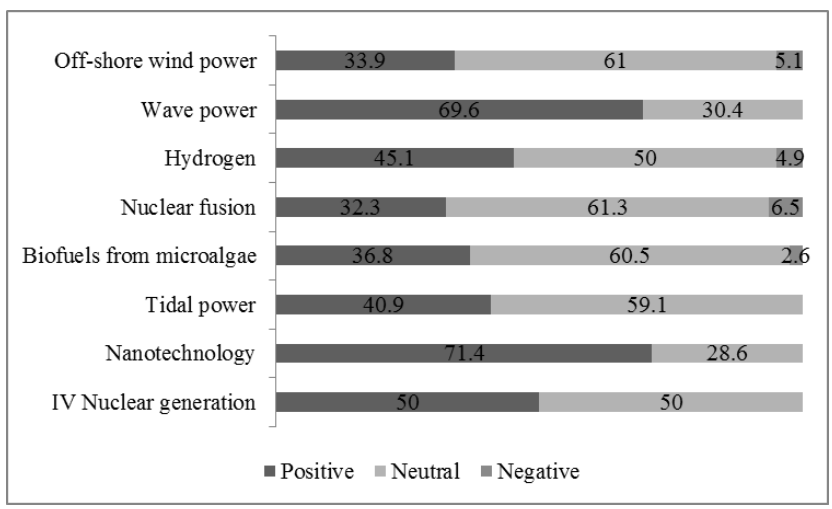

Fig.5 Valuation by type of technology in Spain (\%)

\section{Positive and negative statements regarding emerging technologies}

In Portuguese newspapers, off-shore wind power is more often associated with benefits for the economy. Wave power is commended for its low environmental impact. Articles on hydrogen mention more frequently its climate neutrality, low environmental impact and role in replacing fossil fuels (especially due to its use in motor vehicles). Biofuels from microalgae are usually associated with low environmental impact and climate neutrality. Articles on tidal power refer to its low environmental impact, economic benefits and its role in the energy mix. Nanotechnology articles highlight its capacity for enhancing power or efficiency of other energy technologies.Nuclear fusion is characterised in the Portuguese news by three main advantages: its low environmental impact; the unlimited production of energy; and also as an alternative to energy technologies based on fossil fuels.

In Spanish newspapers, benefits for the economy come on top for off-shore wind power, wave power, tidal power and nanotechnology. Climate neutrality is the most frequently mentioned positive aspect of hydrogen, followed by its role in replacing fossil fuels. Biofuels from microalgae are commended for their climate neutrality and as an alternative to fossil fuels. IV generation nuclear power is valued for its low environmental impact and efficiency.
Nuclear fusion in Spanish news is mostly associated with low environmental impact, unlimited production of energy and replacement of fission energy.

Negative statements on emerging energy technologies in Portuguese newspapers fall mainly into three categories: the technology is not ready or not proven (more frequent concerning fusion and off-shore wind power), the investment cost is high (especially in offshore wind power and hydrogen) and it needs government support (in particular wave power and hydrogen). No negative statements were found regarding nanotechnology.

In Spanish newspapers, negative statements on off-shore wind power mostly concern conflicts with other activities or land uses. The unproven state of the technology is more frequently mentioned with regard to wave power, tidal power and hydrogen. Nuclear fusion and biofuels from microalgae are criticised mostly for the high costs of investment. IV generation nuclear power is considered to be too far in the future and to garner uncertain public acceptance. Again, no negative statements were found regarding nanotechnology.

Comparing the two countries in terms of the positive valuation of nuclear fusion, in Portugal more favourable arguments are used in news articles and the role of fusion as unlimited, clean and an alternative to fossil fuels is more often highlighted. Spanish news articles are in general less optimists (even if they highlight unlimited production, low environmental impact and alternative for nuclear fission). With regard to negative statements, a wider range of arguments against fusion are used in Spain (manly high costs, not proven, too far), whereas criticism in Portuguese articles tends to focus on the unproven nature of this technology.

\section{RESULTS OF THE QUALITATIVE ANALYSIS}

As stated in the methodology section, we have selected one article concerning each emerging energy technology from Spanish and Portuguese newspapers for a qualitative in-depth analysis, totalling 15 articles. This analysis covers the context of the articles, the description of the technology, the positive or negative (or neutral) evaluation performed, the links that are established with other emerging energy technologies, with renewable energies and with conventional energy sources, the feasibility and stage of development, the benefits and costs. For the purpose of this paper we will focus solely on the articles concerning fusion.

Regarding nuclear fusion, we selected the Portuguese article with the title «Nuclear Pros and Cons», an interview with Carlos Varandas, published in Diário de Notícias, on 2013-1209, and the Spanish article with the title «Leading scientists are appealing for the relinquishment of the nuclear fusion reactor», published in La Vanguardia, on 2010-08-26.

\section{A. Context}

In the Portuguese article, it is said that nuclear fusion is often compared with nuclear fission in terms of safety, environmental impact, feasibility, costs and efficiency, which somewhat corresponds to a divide between those that argue in favour of one against the other. Notwithstanding, there are some who advocate for nuclear energy as a core source of 
energy, regardless the method to achieve it, highlighting at the same time that both have advantages and disadvantages which might be differently managed in order to satisfy our societies' energy demand. This is the case of Carlos Varandas, a reputed expert in nuclear research who has been for the past years the President of the Institute of Plasmas and Nuclear Fusion and a member of the Scientific and Technical Committee of the Euratom.

«(Fusion) It's a cheap and almost inexhaustible source of near twenty per cent of the electricity consumed in the world. Nevertheless, nuclear energy still gathers enemies everywhere and the fact is that Portugal will not have a nuclear power plant in the forthcoming years. For Carlos Varandas, scientist and president of the Institute of Plasmas and Nuclear Fusion, this is unavoidably the energy of the future».

According to the Spanish article, doubts about nuclear fusion arise not only from lay persons' knowledge but also from experts views. This article follows the main criticisms to nuclear fusion and particularly to ITER project, conveyed in the words of three physicists - Georges Charpak, Sébastien Balibar and Jacques Treiner, to address the question of whether fusion is a defensible energy technology.

«Opposition to the project is headed by Georges Charpak, Sébastien Balibar and Jacques Treiner. All three have made an appeal for the "relinquishment" of this project because it is "expensive and useless"».

\section{B. Description}

In the Portuguese article, nuclear fusion and nuclear energy in general terms are compared to the immense power generated by the sun. The sun metaphor is indeed a wellknown symbolic reference in media discourse on fusion.

" "Will readers know that life on Earth would not be possible without nuclear? The light and heat that reach the Earth are a tiny part of the light and heat that are generated by nuclear fusion reactions in the centre of the Sun"».

According to the Spanish article, nuclear fusion is still undergoing some complex stages of development and therefore is yet to be proven. This contributes to build an undefined image of fusion and of its contribution to future generations. The following sentence seems to cover all possibilities, but in fact it suggests that fusion is presently consigned to a realm of vague hypothesis.

«The discussion is in terms of whether nuclear fusion is a promising dream or just a costly chimera».

\section{Evaluation}

According to the Portuguese article, fusion energy as part of nuclear energy in a broader sense is vital to provide high amounts of energy in the future. Against all arguments that associate nuclear power exclusively with accidents, bombs and waste, there are also enough arguments to state that either fusion or fission can also be thought-out as 'friendly' sources of energy.

"'Personally, I'm convinced that in the current stage of scientific knowledge and technological development, it is not possible to ensure sustainable and affordable supply of energy to all mankind without the use of nuclear energy"»

«"But nuclear power also has 'good' things. There are many applications of nuclear power in our everyday lives, in areas of activity and knowledge as diverse as medicine, agriculture, environment, archaeology and industry (...) There are many reasons to say that the nuclear is also a friend».

The Spanish article confronts three different perspectives with regard to the role of nuclear fusion in present and future scenarios: the holistic view of the EU and World powers that endorse nuclear fusion research; the science oriented view of the three sceptical scientists above-mentioned; the ecologic view of a French environmental organization, to whom the core subject is the relationship between fusion and climate change.

«In this project, the EU and the World powers have placed our hopes to achieve a clean, cheap and infinite energy for the future during the second half of the century».

«Scientists oppose this project mainly because it "endangers other major investigations" in science and energy».

«The project does not conform to the urgencies of climate change," stated [the environmental organization] France Écologie».

D. Relation to other emerging energy technologies

In the Portuguese article, nuclear fusion is considered the most promising energy technology of the future, but that does not dismiss the possibility to engage with other technologies of the sort in working together for a more consumer friendly supply of energy.

" "In the current stage of scientific and technological knowledge, nuclear fusion (...) has better prospects of success. But we cannot exclude the possibility of developing other energy technologies, as good as or better than nuclear fusion. The more energy sources available, the better it is for consumers (...)"».

E. Relation to mainstream renewable energy technologies

According to the Portuguese article, with regard to mainstream renewables, fusion energy is not seen as a competitor but rather as a key element that supports the very existence of renewable energy systems. This argument takes into consideration only fusion reactions occurring in the core of the Sun.

" "Do you know that many renewables are directly or indirectly dependent on these nuclear fusion reactions?"”

In the Spanish article, the scepticism about fusion strongly contrasts with the positive evaluation of other technologies, namely those that relate to renewable energy sources. Moreover, the high expenditure on fusion research is considered an obstacle to the development of these other technologies.

"'We oppose it because it is an undeveloped technology which is economically wasteful and (...) it can reduce 
investment and public funding toward proven energy technologies such as renewable sources"».

\section{F. Relation to conventional energy systems}

In the Portuguese article, nuclear fusion is thought-out as the best possible solution to replace conventional energy systems based on fossil fuels and traditional nuclear energy.

"“(...) traditional sources of energy are not sufficient to ensure the sustainable development of the entire population of the planet"».

\section{G. Feasibility}

According to the Portuguese article, when feasibility is brought into question, nuclear fusion is less well appraised. For the time being it is considered more of a dream or an endless experiment than a real technological achievement.

"“On Earth [fusion] is still a dream. Man has managed to achieve controlled fusion reactions in two machines (TFTR and JET), but the energy gain was less than the unity (JET yielded 16 megawatts of fusion power, but spent up to $25 \mathrm{MW}$ heat the plasma)"”.

According to the Spanish article, supporters of fusion argue that feasibility is a question of persistency. The main problem to overcome is the availability of suitable materials to work with and not the level of energy to process them.

«The challenge is to work with materials capable of withstanding high energy irradiation».

\section{H. Current stage of development}

The Portuguese article states that regardless the fact that feasibility is yet to be proven, there are positive signs that fusion might be fully accomplished in the future. The ITER device is seen in this context as the state of the art in fusion research and development.

" "In ITER (...) the expectation is to get around 12 to 15

$250 \mathrm{MW}$ of fusion power using the same $25 \mathrm{MW}$ to heat the plasma"».

The Spanish article strongly links nuclear fusion to ITER, despite the existence of other projects related to fusion research methods (e.g. the National Ignition Facility in the USA). Besides the doubts that arise about viability, energy demand and sustainability of fusion energy, the success of ITER is also doubtful and in the best case scenario it will only lead to a fully stage of development in a faraway future.

«If ITER succeeds to generate electricity on a large scale it will not be before the end of the century. Construction began this summer and will end in 2019. The first evidence of fusion reactions will not be presented before 2026. His successor (Demo) will only produce electricity by $2040 »$.

\section{Benefits}

In the Portuguese article, the benefits of nuclear fusion are especially emphasized when compared with nuclear fission's shortcomings.

«"(..) nuclear fusion facilities [when compared with existing fission facilities] are even more powerful (...) much safer and environmentally friendlier because the radioactive fuel is produced inside the reactor itself and there produces no waste in the long term"».
In the Spanish article, supporters are aware that nuclear fusion may be a failure. Nevertheless, there is a considerable optimism about the role of fusion in future energy scenarios.

" "It's a risky bet, but if we are able to do it we will solve humankind energy problems", says Montserrat Torné, General Director for the International Cooperation of the Ministry of Science and Innovation».

\section{J. Costs}

According to the Portuguese article, there is no clear arguments stated towards the costs of nuclear fusion, but some doubts regarding its economic viability emerge when feasibility is again brought into discussion.

«(...) Economic studies predict that a fusion reactor is only viable for gains exceeding 40 [MW] of energy».

In the Spanish article, the costs of nuclear fusion research are mainly linked to the increase of ITER budget. This is an additional argument that helps to support criticism toward nuclear fusion and contributes to build an image of an "expensive and useless" endeavour.

«Criticism of ITER has been reiterated after the budget increase. Initially, EU should contribute 5,900 million euros, but in June it gave the green light to a contribution of 6,600 million (of the total of 15,000 million budget for ten years)».

\section{CONCLUSION}

The quantitative analysis of the articles regarding emerging energy technologies shows some common trends and differences between Portugal and Spain that are worth mentioning. First, it is possible to conclude that nuclear fusion is less covered than offshore wind power and hydrogen in both countries and, additionally, wave power in Portugal. The differences in the proportion of articles written about nuclear fusion are minor when comparing the two countries, whereas the approaches clearly diverge: news coverage in Portugal is more enthusiastic and in Spain more critical.

In the Portuguese case, it is possible to identify a strong concentration on sea energy related technologies such as offshore wind and wave power (with the exception of tidal energy). This trend reflects the greater political and economic support that was given to these technologies at a time when renewable energies were a political priority. The centrality of the global financial crises, mainly from 2009 onwards, led to a steep decrease in the rate of articles published about these and other future energy technologies. In both countries the proportion of articles about nuclear fusion reached its peak in 2010 (the year of an important meeting of the board of directors of ITER), declining sharply afterwards. This also indicates that media interest on nuclear fusion is primarily linked to the decision processes, research activities and budgetary issues that arise from the ITER cooperation framework.

Portugal and Spain differ significantly with regard to the overall evaluation of the emergent energy technologies. In Portugal there is a clear orientation towards a positive evaluation of all the technologies surveyed, especially in the cases of nanotechnology, biofuels from microalgae and 
offshore wind power and less in the cases of nuclear fusion and wave power. In Spain there is a more neutral orientation in the coverage of all technologies, with the exceptions of nanotechnology and wave power, which are more frequently evaluated in a positive way. Finally, it is in Portugal that we find a more diverging trend in the evaluation of nuclear fusion: more articles with positive assessments, which are mainly linked to its low environmental impact and unlimited energy, but also more articles with negative assessments, mainly linked to the fact that the technology is still not ready.

Nuclear fusion is primarily appreciated in both countries for its low environmental impact, unlimited production of energy and the possibility to replace nuclear fission and fossil fuels. Other technologies such as wave power, biofuels from microalgae and nanotechnology in Portugal, or wave power and IV nuclear generation in Spain, are also valued for its low environmental impacts; we have also found that a considerable number of news articles from Portugal and Spain present hydrogen and biofuels from microalgae as credible alternatives to fossil fuels. Additionally, wave power is also frequently considered as an unlimited source of energy in Spain.

Nuclear fusion is negatively evaluated in Portugal, especially with regard to its stage of development (incipient) and costs of investments. It is also considered the only technology that consumes more energy than it produces. In Spain, fusion is considered the most costly technology of all, but still shows less negative evaluations when compared to hydrogen with regard to the stage of development and to IV nuclear generation with regard to public acceptance and future prospect.

\section{REFERENCES}

[1] L. Schmidt, A. Horta, S. Pereira, S. Public discourse on (old and new) nuclear energy technologies before and after Fukushima. Proceedings Pre-Congress Conference Sustainability and Environmental Sociology, Yokohama: SUSKEN / JAES / ISA RC24, 2014, pp. 99-117

[2] M. Fontes, J. Ferreira, C. Sousa. "The multi-spatial dynamics of niche trajectory: the case of the wave energy technological niche." Paper presented at the 5th International Sustainability Transitions Conference Utrecht 27-29 August 2014

[3] A. Horta, C. Oliveira, Construção mediática das energias renováveis: as centrais eólicas e solares de 2001 a 2013, Relatório de Pesquisa, Lisboa, ICS ULisboa, 2014

[4] H. Mendes, "Visibilidade da Ciência nos Mass Media: A Tematização da Ciência nos Jornais Público, Correio da Manhã e Expresso", in M. E. Gonçalves (Org.) Os Portugueses e a Ciência, Lisboa, Publicações Dom Quixote, 2002, pp. 31-78.

[5] L. Schmidt, "Comunicar a Ciência: o papel dos media e os problemas científico-ambientais", in L. Schmidt, J. P. Cabral (Eds.), Ciência e Cidadania - Homenagem a Bento de Jesus Caraça, Lisboa, Imprensa de Ciências Sociais, 2008, pp. 85-112.

[6] R. Ramos, A. Carvalho, A. "Science as rhetoric in media discourses on climate change", in J. Strunck, L. Holmgreen, L. Dam (Eds.) Rhetorical aspects of discourse in present-day society, Cambridge, Cambridge Scholars Press, 2008, pp. 223-247. 